Revista Destaques Acadêmicos, Lajeado, v. 11, n. 2, 2019. ISSN 2176-3070

DOI: http://dx.doi.org/10.22410/issn.2176-3070.v11i2a2019.2241

http://www.univates.br/revistas

\title{
A FUNDAMENTALIDADE DO VÍNCULO ENTRE DIREITOS HUMANOS E DIREITO AMBIENTAL
}

\author{
Lauren de Oliveira Schaefer ${ }^{1}$
}

Resumo: O presente artigo visa explorar o significado e a evolução dos Direitos Humanos e do Direito Ambiental, de forma relacioná-los para obter uma visão consciente de sua imprescindibilidade. Por meio de estudo bibliográfico de obras de autores consagrados no assunto, foram obtidos fatos e informações importantes no que tange à evolução e aos propósitos da criação de proteções ao meio ambiente. Os resultados alcançados demonstram o quanto um ambiente equilibrado é fundamental para dispor de qualidade de vida e do cumprimento dos direitos humanos, considerando o seu desenvolvimento e o da sociedade na qual está inserido, dependendo, sobretudo, da ação humana.

Palavras-chave: direito ambiental, direitos humanos, Constituição Federal.

\section{INTRODUÇÃO}

Diante de tantos acontecimentos recorrentes de atos humanos, por costume, acaba-se dando importância a fatos que, aparentemente, são mais relevantes à vida cotidiana do que outros. Muito fala-se sobre a dignidade da pessoa humana e sobre os direitos humanos, que, como cita Barroso (2010, p. 21), “...são duas faces de uma só moeda”, porém diferem, pois, o primeiro é pertinente da filosofia, de modo a manifestar os valores morais que caracterizam todas as pessoas, e tornam-nas merecedoras do mesmo respeito e estima, enquanto o segundo, sendo voltado ao Direito, é a tradução das posições jurídicas tuteladas para com a pessoa humana, por normas e ações judiciais. Todavia, a dignidade da pessoa humana e os direitos humanos são, frequentemente, lembrados como apenas necessidades a serem atendidas e respeitadas socialmente, em relações interpessoais, e não ambientalmente.

A importância de um ambiente adequado e salutífero seguidamente é deixada em segundo plano, perante situações consideradas mais significativas, como, por exemplo, a econômica, por parecerem mais primordiais a curto prazo. Por esse motivo, a atenção no que tange à natureza e sua necessidade para

1 Acadêmica do Curso de Direito da Universidade do Vale do Taquari - Univates. 
garantir o cumprimento efetivo dos direitos humanos é esquecida. Na década de 70, de acordo com Comparato (2015), verificou-se a necessidade de convocar a Conferência das Nações Unidas sobre o Meio Ambiente Humano, durante reunião em Estocolmo de 5 a 16 de junho de 1972, que, através de uma Declaração, proclamou, dividida em diversos princípios, a responsabilidade humana e sua dependência com base na natureza, a fim de guiar e inspirar atitudes apropriadas e inclinadas ao bem-estar humano e ambiental, reciprocamente. A criação desse documento, o primeiro em âmbito internacional, proporcionou o reconhecimento de um meio ambiente de qualidade como um direito humano, que permite ao homem viver com dignidade.

Neste artigo, busca-se realizar uma relação entre os conceitos e a importância dos Direitos Humanos e do Direito Ambiental, com intuito de verificar como se associam e conferem fundamental atuação para o requerido equilíbrio das sociedades, da ambiência, e para uma convivência pacífica e virtuosa entre os seres humanos e os demais animais. Através de pesquisas bibliográficas de obras de autores renomados nos assuntos, com apresentação de histórico e conceituação de ambas temáticas, será apresentado o seu liame, com o propósito de promover um pensamento crítico e progressista sobre o assunto, que possa desenvolver a mentalidade do leitor sobre a importância de agir corretamente no que se refere ao ambiente.

\section{O CONCEITO DE DIREITOS HUMANOS E SEU DESENVOLVIMENTO JURÍDICO}

Segundo Ramos (2015), pode-se definir o termo "Direitos Humanos" como um conjunto de direitos que são fundamentais para que tenhamos uma vida humana baseada em igualdade, dignidade e liberdade. Não há uma classificação de quais são esses direitos de forma predeterminada, pois na sociedade hodierna na qual eles estão inseridos podem ocorrer modificações para atender à demanda de suas necessidades sociais, em decorrência de mudanças contemporâneas, de forma a serem traduzidas juridicamente, e aditadas no rol dos direitos humanos.

Mazzuoli (2016) afirma que esse conceito é inerente ao direito internacional público, pois refere-se a direitos garantidos por normas de caráter internacional, por meio da celebração de tratados ou declarações entre Estados, a fim de proteger todas as espécies de direitos dos indivíduos constituintes de seu domínio. Tais normas podem provir do chamando sistema global, que pertence à Organização das Nações Unidas (ONU) ou dos sistemas regionais de proteção, que são o europeu, o interamericano e o africano. De acordo com o autor, a proteção jurídica dos direitos das pessoas emana de ordem estatal, que é interna, ou de ordem internacional. A primeira, que protege os direitos do cidadão, suscita a proteção de um direito fundamental da pessoa, e a segunda, de um direito humano. Essa distinção surgiu quando os direitos fundamentais, através do aumento das relações internacionais e da ânsia pela proteção dos 
direitos em alçada superior de defesa contra violências de autoridades estatais, tornaram-se pertinentes ao direito internacional.

Sobre a importância da origem do indivíduo na proteção dos direitos humanos, Mazzuoli (2016, p. 21) alega que "...não importa a nacionalidade da vítima, bastando ter sido ela violada em seus direitos por ato de um Estado sob cuja jurisdição se encontrava". O autor ainda exemplifica que se ocorre a violação de direitos de um cidadão francês no Brasil, o sistema interamericano de Direitos Humanos (Comissão e Corte Interamericanas de Direitos Humanos) é competente, já se um brasileiro tiver seus direitos violados na Guiana Francesa, que é um departamento ultramarino da França, a competência é do sistema europeu de Direitos Humanos (Corte Europeia de Direitos Humanos).

Ramos (2015) destaca que direitos humanos representam valores essenciais, de modo que sua fundamentalidade formal se dá por meio da vinculação à Constituição ou tratados internacionais, e o modo material quando não são expressos, mas substanciais para o cumprimento da dignidade humana. A despeito de diferirem no conteúdo, possuem quatro ideias principais em comum: universalidade, essencialidade, superioridade normativa e reciprocidade. $\mathrm{O}$ autor esclarece que "a universalidade consiste no reconhecimento de que os direitos humanos são direitos de todos, combatendo a visão estamental de privilégios de uma casta de seres superiores" (RAMOS, 2015, p. 28); a essencialidade significa que os direitos humanos possuem valores necessários e devem ser preservados. Já a superioridade exprime a proeminência dos direitos humanos em relação às demais normas, enquanto a reciprocidade é o arranjo de direitos que une a sociedade.

Ao diferenciar os termos "direitos do homem", "direitos humanos" e "direitos fundamentais", temos que direitos do homem

Trata-se de expressão de cunho jusnaturalista que conota a série de direitos naturais (ou seja, ainda não positivados) aptos à proteção global do homem e válidos em todos os tempos. São direitos que, em tese, ainda não se encontram nos textos constitucionais ou nos tratados internacionais de proteção. Contudo, nos dias atuais, salvo raros exemplos, é muito difícil existir uma gama significativa de direitos conhecíveis que ainda não constem de algum documento escrito, quer de índole interna ou internacional. (MAZZUOLI, 2016, p. 22)

Direitos fundamentais, por sua vez, segundo o autor, são a proteção interna dos direitos do cidadão, que já se encontram positivados em Cartas Constitucionais, sendo direitos assegurados em uma ordem jurídica, em tempo e espaço determinados. Tais elementos devem constar na Constituição para que esta não perca a coerência de sua existência, como cita Mazzuoli (2016, p. 22), segundo o "art. 16 da Declaração (francesa) dos Direitos do Homem e do Cidadão de 1789: 'A sociedade em que não esteja assegurada a garantia dos 
direitos nem estabelecida a separação dos poderes não tem Constituição' ". Os direitos humanos, diferentemente, referem-se aos direitos positivados em tratados e declarações previstos em esfera internacional.

Figura 1 - Os três tipos de direitos

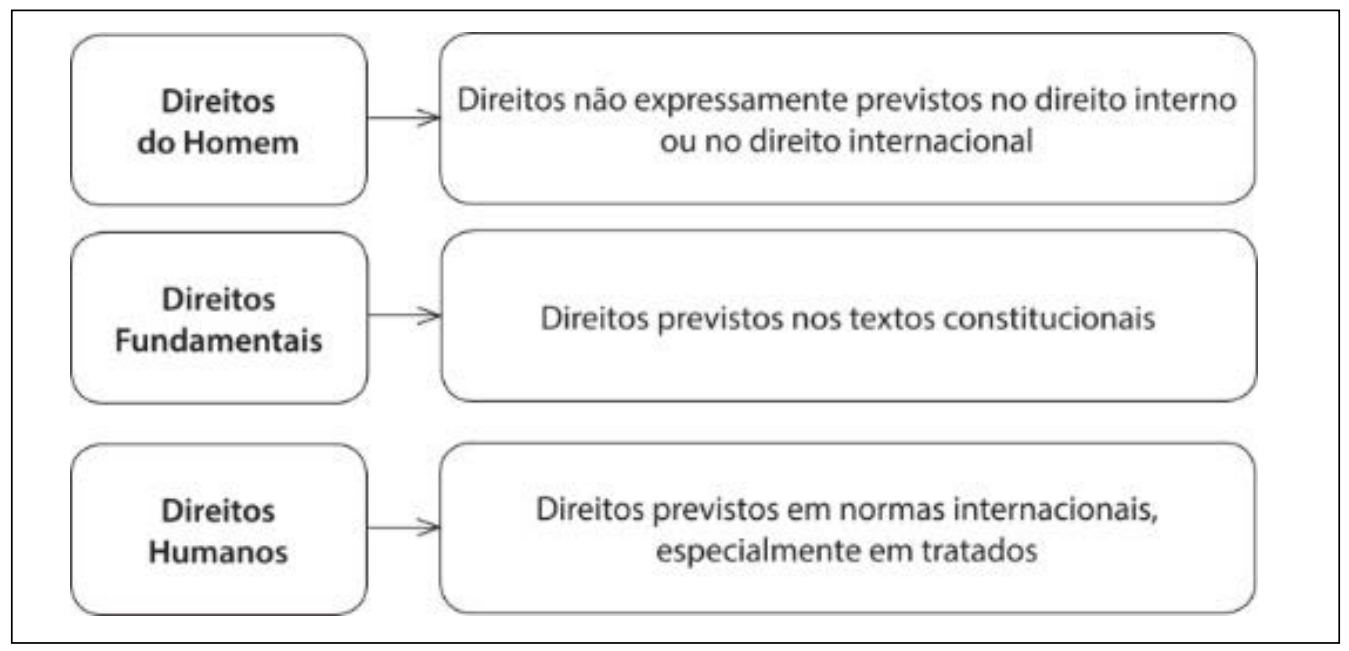

Fonte: Mazzuoli (2016, p. 24)

$\mathrm{O}$ autor, para destacar a diferença entre direitos fundamentais e direitos humanos, declara que os direitos humanos abrangem muito mais e de forma mais ampla do que os direitos fundamentais, por um ser interno e outro internacional, não tendo o segundo uma aplicação tão extensa quanto o primeiro. A essência dos direitos humanos é o confronto contra a violência, a intolerância e a sujeição.

Tão importante quando o conceito de direitos humanos, é sua evolução histórica no ordenamento jurídico internacional por meio da criação de normas que atingem diversos países, e, consequentemente, têm grande alcance à população mundial. Pelo seu desenvolvimento, verifica-se um efetivo progresso na proteção dos direitos fundamentais, com abundante evolução na abrangência de seu cumprimento.

\subsection{Evolução das principais normas relativas aos Direitos Humanos}

a) A Magna Carta, segundo Comparato (2015), foi o primeiro documento a positivar os direitos dos cidadãos ingleses. Assinada pelo rei João Sem-Terra, a Carta estipulava que o rei deveria seguir a lei imposta, e não mais governar como bem entendesse, devido à pressão posta pelos nobres ingleses, chamados barões, que chegaram a ocupar Londres armados, e os líderes da igreja, insatisfeitos com o reinado da época. Além dos direitos dos barões e da Igreja Católica 
mencionados na Carta, ela também tratou substancialmente dos direitos de mulheres e crianças, e da necessidade de declarar alguém como culpado de um crime antes de puni-lo.

b) Castilho (2015) aponta a Petição de Direitos, de 1628, como causadora do começo do constitucionalismo moderno. Na Inglaterra, Carlos I, inoperante sobre a rebeldia na Escócia e a insatisfação na Irlanda, se viu no compromisso de convocar um parlamento. Porém, acostumado a governar com poder absoluto, sentiu a forte oposição que sofrera do Parlamento. Os deputados, sob liderança de Sir Edward Coke, apresentaram ao rei uma petição de direitos que exigia mais poder a eles, e menos controle do soberano, que acabou por dissolver o Parlamento, e governar rigidamente por mais 11 anos. Após esse tempo, convocou um novo parlamento, e em menos de um ano o dissolveu, mas com represálias: a declaração da revolução puritana, que pôs fim ao absolutismo na Inglaterra, ao consolidar o regime político monárquico parlamentar. A guerra civil de 1642 continuou até 1688 , ano da Revolução Gloriosa, que pôs fim ao poder do catolicismo. Este período foi chamado de Revolução Inglesa do século XVII, e retratou a primeira crise do absolutismo.

c) Comparato (2015) relata que o habeas corpus já existia na Inglaterra antes mesmo da Magna Carta, em casos de prisão arbitrária por mandado judicial, mas devido à ausência de regras processuais seu êxito era diminuto. Com a criação da Lei de 1679, que tinha como designação "uma lei para melhor garantir a liberdade do súdito e para prevenção das prisões no ultramar", a carência destas regras foi suprida, e asseverou ao povo garantias processuais. Segundo Castilho (2015), o Habeas Corpus Act, destaque no reinado de Carlos II, instituiu e reforçou ao já existente direito de que o sujeito que foi detido deve ser conduzido a um tribunal para que, legalmente, sua punição seja decidida.

Trata-se da mais sólida garantia de liberdade individual, eis que tira dos déspotas a faculdade de proceder a prisões arbitrárias. Há que se reconhecer, também, a importância histórica do documento, que serviu de inspiração e modelo para todas as garantias criadas a partir de então, passando a ser utilizado, além do caso de prisão, também nos casos de ameaça e constrangimento à liberdade individual de ir e vir (CASTILHO, 2015, p. 64)

Para Comparato (2015), o habeas corpus tem extrema importância histórica, pois sua regulamentação tornou-se garantia judicial, feita para produzir a liberdade de locomoção, transformando-se em referência para liberdades fundamentais criadas posteriormente. 
d) Comparato (2015) relata que, em 1688, o Príncipe Guilherme de Orange e sua mulher, professantes da religião protestante, tomaram a coroa, por convite dos partidos, e aceitaram a Declaração de Direitos votada pelo Parlamento, a qual pôs fim ao regime de monarquia absoluta, em ato que declarou direitos, proclamou a liberdade de súditos e definiu a sucessão da coroa. De suma importância, regulou a deliberação parlamentar, as eleições livres e a liberdade de expressão no Parlamento.

Nesse viés, a Declaração dos Direitos do Homem e do Cidadão, de 1789, inspirada nos ideias iluministas, e aprovada na Assembleia Nacional Constituinte da França, proclamou as liberdades e os direitos fundamentais do homem, envolvendo toda a sociedade. Tal documento serviu de inspiração para as constituições francesas de 1793 e para a atual, e foi base da Declaração Universal dos Direitos Humanos, pela Organização das Nações Unidas.

e) Após diversos acontecimentos históricos contribuintes para a evolução dos direitos humanos, como cita Castilho (2015), a Convenção de Genebra, e, por conseguinte, a Constituição de Genebra, as Constituições Francesa, Mexicana, Alemã e tantos outros fatos ocorridos, foi adotada a Carta das Nações Unidas no segundo pós-guerra, em 1945. Sobre tal, Mazzuoli (2016) explica que o Direito Internacional dos Direitos Humanos passou a ser efetivado como autônomo no direito internacional público, já que antes, por mais que existissem normas protetivas aos direitos humanos, sentia-se falta de um sistema característico. Segundo o autor, com o surgimento das Nações Unidas, alcança-se uma nova ordem internacional, que rege relações internacionais, com a preocupação de manter e promover paz e segurança, a relação gentil entre Estados, a cooperação econômica, social e cultural, a obtenção de um padrão internacional de saúde, a proteção ao meio ambiente, e especificamente, a promoção dos direitos humanos, não importando raça, sexo, língua, religião, sistemas políticos, econômicos ou culturais.

$\mathrm{O}$ respeito às liberdades fundamentais e aos direitos humanos, com a consolidação da Carta da ONU, passou a ser preocupação internacional e propósito básico das Nações Unidas. Nesse cenário, os problemas internos dos Estados e suas relações com os seus cidadãos passam a fazer parte de um contexto global e proteção, baseado na cooperação internacional e no desenvolvimento das relações pacíficas entre as Nações. Daí o motivo de a Carta da ONU, desde o seu segundo considerando, ter ficado impregnada da ideia de respeito aos direitos humanos e liberdades fundamentais para todo (MAZZUOLI, 2016, p. 66) 
De acordo com Comparato (2015), o Conselho Econômico e Social das Nações Unidas, respeitando o art. 68 da Carta, aprovou o estatuto da Comissão de Direitos Humanos, que, futuramente, em 2006, viria a ser substituída pelo Conselho de Direitos Humanos. Fundado em 2006, o Conselho tem, atualmente, 47 Estados-membros eleitos por um período de 3 anos, por meio de votação direta e secreta, tendo o Brasil sido eleito em 2016, com início do mandato em 2017. Para tal eleição, segundo a ONU, é considerada "a contribuição dos Estados candidatos à promoção e proteção dos direitos humanos, bem como seus compromissos e promessas voluntárias a este respeito".

f) Segundo Ramos (2015), a Declaração Universal dos Direitos Humanos de 1948, elaborada pela chamada na época de Comissão de Direitos Humanos, tinha o intuito de ser estágio anterior à criação de um tratado internacional de direito humanos, e, posteriormente, um modo de assegurar o respeito a esses direitos e lidar com os casos de violação. Castilho (2015) ressalta que a Declaração foi aprovada pela Resolução n. 217-A (III) da Assembleia Geral, o que significa que não possuía forma de tratado multilateral. Tanto Castilho (2015), quanto Comparato (2015) concordam que há excesso de formalismo, e que não importa o nome que se dá ao instrumento reconhecedor, mas sim, que os direitos humanos são de suma importância e devem ser protegidos. Castilho (2015) discute sobre a influência internacional que a Declaração obteve ao ser referência para Constituições criadas após 1948, e também para tratados internacionais, e cita o pronunciamento expresso da Corte Internacional de Justiça que declarou o valor jurídico da Declaração.

Ao longo de seus artigos, a Declaração Universal dos Direitos Humanos desenvolve a ideia que quer transmitir, isto é, a definição de vida digna e os direitos pertinentes ao ser humano. Mazzuoli (2016) salienta que a Declaração ocupou os lapsos da Carta das Nações Unidas, ao firmar um código ético universal na defesa e proteção dos direitos humanos, provendo-lhe nova potência à obrigação jurídica de proteção desses direitos, já constantes na Carta.

g) Comparato (2015) relata que a Convenção para a Proteção dos Direitos Humanos e das Liberdades Fundamentais elaborada pelo Conselho da Europa, e celebrada em 1950, buscava a promoção de uma unidade europeia, de forma a proteger os direitos humanos e impulsionar o progresso, social e economicamente. Segundo o autor, essa Convenção não possuía nada de inovador quando comparada à Declaração Universal de Direitos Humanos, mas a celebração da Carta Social Europeia, em 1961, garantiu a proteção formal dos direitos econômicos e socioculturais, e que, futuramente, em 1992, seria complementada com a entrada de um protocolo adicional que exprimia quatro novos direitos. São eles: à igualdade de oportunidades e abordagem no meio trabalhista, à informação 
sobre a empresa na qual o cidadão trabalhava a possibilidade dos trabalhadores de opinarem sobre as condições e locais de trabalho, e o direito dos idosos à proteção social.

h) Anterior à Convenção Americana sobre Direitos Humanos, segundo Mazzuoli (2016), ocorreu a criação do Sistema Interamericano de Proteção dos Direitos Humanos, quando da proclamação da Carta da Organização dos Estados Americanos (Carta de Bogotá) de 1948. A Convenção, por sua vez, é o instrumento fundamental desse Sistema, que assinada em 1969, acabou por entrar em vigor no plano internacional somente em 1978, após 11 ratificações. O autor expõe que ela foi ratificada pelo Brasil em 1992, e promulgada em 6 de novembro do mesmo ano pelo Decreto $\mathrm{n}^{\circ} .678$.

Mazzuoli (2016), ao sintetizar os objetivos da Convenção, profere que a proteção prevista nela é complementar à oferecida pelo Direito interno dos Estados. Como ele explica, ela não é "supletória", ou seja, não é retirado o direito dos Estados de amparar e preservar os direitos dos cidadãos pertencentes à sua jurisdição, mas através da Convenção, o Sistema interfere nos casos em que as garantias previstas são descumpridas pelo Estado. $\mathrm{O}$ autor situa as duas divisões da Convenção Americana, que são a Comissão Interamericana de Direitos Humanos e a Corte Interamericana de Direitos Humanos. À Comissão é cabível a procedência ao juízo de admissibilidade das petições ou comunicações desenvolvidas por qualquer pessoa ou grupo, ou entidade não governamental tida como legal em pelo menos um Estado-membro da Organização dos Estados Americanos (OEA), enquanto a Corte é responsável pela ação proposta, e os casos, provenientes destes Estados, relatados sobre violação de direitos humanos.

Carvalho (2015) destaca que a Declaração Americana é anterior à Declaração Universal dos Direitos Humanos, e que, a partir dela, foi reconhecida a universalidade dos direitos humanos, ao declarar que os direitos do homem não dependem de ele ser de certo Estado, basta ele ter condição humana, o que consta no preâmbulo.

i) Comparato (2015, p. 398) descreve a Convenção para a Proteção do Patrimônio Mundial, Cultural e Natural, realizada no ano de 1972, na cidade de Paris, França, como "o primeiro documento normativo internacional que reconhece e proclama a existência de um 'direito da humanidade', tendo por objeto, por conseguinte, bens que pertencem a todo gênero humano e não podem ser apropriados por ninguém em particular". Os respectivos Estados nos quais se encontram esses bens devem prestar contas internacionalmente sobre a condição dos mesmos, pois são apenas administradores fiduciários, e, tem por fim, o dever de protegê-los contra a degradação natural e social.

j) De acordo com Mazzuoli (2016), o sistema africano de direitos humanos foi criado em 1981, com a Carta Africana dos Direitos 
Humanos e dos Povos, que entrou em vigor somente em 1986. Deste ano até 1998, o sistema africano contava somente com uma Comissão. Após, houve a criação da Corte Africana dos Direitos Humanos e dos Povos, que vigorou apenas a partir de 2004. “....a Carta Africana foi muito além das outras convenções e instrumentos regionais e globais ao prever, de forma ampla e detalhada, os deveres individuais" (MAZZUOLI, 2016, p. 142).

A respeito dos outros continentes, Mazzuoli (2016, p. 153) afirma que "o Mundo Árabe dispõe apenas de uma Carta Árabe de Direitos Humanos, não perfazendo (ainda) um verdadeiro 'sistema' regional de proteção", e que na Ásia não há nenhum tratado internacional de proteção aos direitos humanos, nem mesmo perspectiva de criação de uma Comissão ou Corte.

k) Conforme Comparato (2015), a Convenção sobre o Direito do Mar, assinada dez anos depois da Convenção para a Proteção do Patrimônio Mundial, Cultural e Natural, trouxe os direitos fundamentais da humanidade no que tange aos oceanos e mares, discutindo de um lado o interesse econômico na exploração dos fundos e subsolos marinhos e oceânicos, e limites de jurisdição dos países, e de outro lado, a harmonia na conservação e resguardo do ambiente marinho. Foram reconhecidos o leito do mar, os fundos marinhos e o subsolo como patrimônio da humanidade.

1) Comparato (2015) relembra, a já citada anteriormente, Conferência das Nações Unidas sobre o Meio Ambiente Humano, realizada em 1972, em Estocolmo. Ele a cita como o início da campanha mundial pela preservação do ambiente, que abriu caminho, para vinte anos depois, outras duas Convenções serem assinadas: a Convenção sobre a Diversidade Biológica (entrou em vigor em 1993) e a ConvençãoQuadro sobre Mudança do Clima (entrou em vigor em 1994). Em ambas Convenções, o objetivo é inserir o princípio fundamental da solidariedade em todo o mundo; entre as nações, povos, e entre gerações atual e futura, de forma que a geração atual garanta uma boa qualidade de vida à geração futura. Esse dever, segundo o autor, evidentemente se relaciona com as condições de degradação ambiental do planeta, que representam risco para a ecosfera, e para toda a humanidade.

No mundo contemporâneo, no entanto, a preservação da biodiversidade tem sido gravemente ameaçada pelo sistema capitalista de produção. De um lado, os atuais padrões de consumo, no mundo rico, incentivam os países subdesenvolvidos a exportar mercadorias, como as madeiras nobres, cuja extração provoca a degradação do meio ambiente. De outro lado, os mesmos países subdesenvolvidos são pressionados a admitir a instalação, em seu território, de indústrias altamente poluentes, cujo funcionamento é 
vedadonos países ricos. Por outrolado, éfundamental reconhecer que nenhuma espécie de ser vivo pode ser monopolizada por ninguém, e que o genoma de qualquer espécie biológica é um patrimônio universal, cujos componentes não podem, legitimamente, ser objeto de apropriação (COMPARATO, 2015, p. 446)

Ao citar dados revelados em pesquisas de 2005, Comparato (2015) se assusta com o exposto: bilhões de pessoas não possuíam acesso à água potável; a concentração de dióxido de carbono havia aumentado em 32\% desde a Revolução Industrial; um percentual de 10 a 30\% das espécies de anfíbios, mamíferos e aves estavam ameaçadas de extinção, e $1 / 4$ dos peixes sujeitados à enorme exploração empresarial. $\mathrm{O}$ autor traz a informação de que o relatório de 1987 da Comissão Mundial sobre o Desenvolvimento Econômico das Nações Unidas definiu o desenvolvimento sustentável como sendo "o desenvolvimento que satisfaz as necessidades do presente, sem comprometer a aptidão das futuras gerações a satisfazer suas próprias necessidades" (COMPARATO, 2015, p. 443).

Conectada diretamente às gerações atual e futura está a importância da proteção ambiental, visando um ambiente de qualidade para todos os seres. A exploração ambiental interfere drasticamente na vida humana por afetar consumos básicos como de água e alimentos. De acordo com a FAO (Organização das Nações Unidas para Alimentação e Agricultura), 41 países sofrem com a falta de comida, isso, pois, longos conflitos armados e condições climáticas adversas fazem com que a necessidade por ajuda aumente.

\section{A RELAÇÃO ENTRE DIREITOS HUMANOS E DIREITO AMBIENTAL}

A proteção do meio ambiente brasileiro, segundo Sirvinskas (2016), pode ser dividida em três períodos. O primeiro começa com o descobrimento do país em 1500, e prolonga-se até 1808, com a vinda da Família Real Portuguesa, em que são criadas normas de proteção aos recursos naturais, como o paubrasil, as sesmarias nas terras litorâneas, as florestas, matas e arvoredos, e o regulamento à derrubada de árvores. O segundo período, que é iniciado após a vinda da Família Real, e estende-se até a criação da Lei da Política Nacional do Meio Ambiente em 1981, foi marcado pela exploração descomedida do meio ambiente, e pela proteção de tal pelo Código Civil, além da criação da Lei de Terras em 1850, da primeira reserva florestal no Acre em 1911, do Código Florestal de 1934, do Estatuto de Terra em 1964, do Código Florestal de 1965, da Lei de Proteção à Fauna de 1967, do Conselho Nacional de Controle da Poluição Ambiental em 1967, e da Lei sobre a Política Nacional do Meio Ambiente em 1981.

O terceiro período citado pelo autor inicia-se em 1981, após a criação da Lei da Política Nacional do Meio Ambiente, e segue até os dias atuais. Essa fase, desde seu início, foi marcada pelo intuito de proteger o meio ambiente de 
maneira integral através de um sistema ecológico integrado relacionado com a vigência da Lei sobre Ação Civil Pública de 1985, da Constituição Federal de 1988, da Lei de 1991 sobre política agrícola, das Unidades de Conservação criadas em 2000, e do novo Código Florestal de 2012.

Conforme Fiorillo (2015), a edição da Lei $n^{\circ}$ 6.938/1981, que instaurou a Política Nacional do Meio Ambiente, foi uma evolução doutrinária que passou a definir o ambiente "como uma interação de ordem química, física e biológica que permite, abriga e rege a vida em todas as suas formas" (p. 39). Tal lei, segundo ele, significou um grande estímulo nas tutelas dos direitos metaindividuais, que impulsionou a edição da Lei $n^{\circ} 7.347 / 1985$, que coloca à disposição ações processuais para quando houver lesão ou ameaça de lesão ao meio ambiente, ao consumidor, aos bens e direitos de valor artístico, estético, histórico, turístico e paisagístico.

Fiorillo (2015) menciona o legislador constituinte de 1988, que admitiu a tutela de direitos coletivos, pois compreendeu a existência de uma terceira espécie de bem, que é o bem ambiental, e utiliza-se do disposto no caput do art. 225 da Constituição Federal, que prevê que "todos têm direito ao meio ambiente ecologicamente equilibrado, bem de uso comum do povo e essencial à sadia qualidade de vida, impondo-se ao Poder Público e à coletividade o dever de defendê-lo e preservá-lo para as presentes e futuras gerações".

A Declaração Universal dos Direitos Humanos de 1948 reza que: "Toda pessoa tem direito a um nível de vida próprio a garantir sua saúde, seu bem-estar e de sua família". A Declaração das Nações Unidas sobre o Meio Ambiente Humano, firmada em Estocolmo, Suécia, em 1972, em seu Princípio 1, diz que "o homem tem um direito fundamental à liberdade, à igualdade e a condições de vida satisfatórias, num ambiente cuja qualidade lhe permita viver com dignidade e bem-estar. Ele tem o dever solene de proteger e melhorar o meio ambiente para as gerações presentes e futuras". Tais princípios foram adotados pelo nosso constituinte, que os arrolou expressamente no art. 225 da CF (SIRVINSKAS, 2016, p. 83)

Segundo Canotilho (2015), assim como os direitos fundamentais, o direito ambiental também sofreu uma cronologia de gerações de direitos, até a subjetivação do direito ao ambiente como direito fundamental ambiental. "A dimensão antropológica deste direito era particularmente acentuada por todos aqueles que insistiam na pessoa humana e na sua dignidade como raiz indeclinável da moralidade ambiental antropocêntrica bem no sentido kantiano" (CANOTILHO, 2015, p. 23 e 24).

Analisando o art. 225 da Constituição Federal de 1988, Fiorillo (2015) divide-o em quatro fragmentos para explicá-lo melhor. A primeira parte indica "...como direito de todos, a existência do direito a um meio ambiente ecologicamente equilibrado" (p. 48), em que o termo todos abrange brasileiros 
e estrangeiros residentes no país, conforme definição do art. $1^{\circ}$, III da CF/88. Dessa forma, toda e qualquer pessoa humana está submetida ao direito positivo necessário para exercer os direitos ambientais no país. A segunda parte referese ao termo bem ambiental. A Constituição, ao mencionar o direito de todos a um meio ambiente ecologicamente equilibrado, indica a vinculação de um direito a um bem de uso comum dos cidadãos e essencial à boa qualidade de vida. A terceira parte reporta-se à estrutura finalística do direito ambiental, em que o direito ao ambiente é bem de uso comum, e ao ser considerado difuso, deve ser necessário para obter-se qualidade de vida.

Com efeito, um dos princípios fundamentais da República Federativa do Brasil é o da dignidade da pessoa humana, e, para que uma pessoa tenha a tutela mínima de direitos constitucionais adaptada ao direito ambiental, deve possuir uma vida não só sob o ponto de vista fisiológico, mas sobretudo concebida por valores outros, como os culturais, que são fundamentais para que ela possa sobreviver, em conformidade com a nossa estrutura constitucional. E é exatamente por conta dessa visão que apontamos o critério de dignidade da pessoa humana, dentro de uma visão adaptada ao direito ambiental, preenchendo o seu conteúdo com a aplicação dos preceitos básicos descritos no art. $6^{\circ}$ da Constituição Federal (FIORILLO, 2015, p. 50)

Fiorillo (2015) ao mencionar o bem ambiental como fundamental, de acordo com a Carta Constitucional, defende que por ser uma questão de importância evidente à vida, merece proteção do Poder Público e de toda a coletividade, num caso de dever, e não apenas de norma moral, pois essa proteção de valores ambientais constitui a sociedade em suas instituições, e se justapõe às regras e costumes tradicionais de organizações. A quarta parte é o resguardo das futuras gerações, que já pelo termo, demonstra a intenção de prover responsabilidade de tutela dos valores ambientais, não somente à geração atual, mas às próximas.

De acordo com Amorim (2015), a constatação da necessidade de proteger o meio ambiente, e de sua ligação com a dignidade da pessoa humana, foi consequência da evolução da percepção da sociedade, e acabou por aparecer no direito internacional na segunda metade do século $\mathrm{XX}$, criando "sua proteção jurídica e o reconhecimento da importância da manutenção de sua qualidade e diversidade para a dignidade da pessoa humana e seu pleno desenvolvimento" (AMORIM, 2015, p. 115).

Segundo o autor, no processo de desenvolvimento e sistematização contemporâneo do direito internacional do meio ambiente, a ONU foi impulsora e detentora das forças políticas devotadas à sua realização e efetivação. Amorim (2015) ressalta que, a partir de 1945, a Organização começou a executar a consolidação do sistema internacional de proteção da pessoa humana, bem 
como do meio ambiente. Já em 1968, a Assembleia Geral da ONU aprovou a Resolução 2.398 (XXIII), na qual foi reconhecido que a relação do homem com o meio ambiente passava por intensas modificações em consequência dos avanços na tecnologia e na ciência, os quais podem provocar riscos ao bemestar social e à saúde, bem como, aos direitos humanos. Contudo, não somente de avanços utiliza-se o autor para caracterizar os direitos fundamentais. A segurança ambiental apresenta-se de diversas formas, e sua ausência pode resultar em instabilidade para o ser humano, como nas disputas por recursos naturais, especialmente em países com substâncias em quantidade abundante, sendo grande parte no continente africano e no Oriente Médio.

Conforme Amorim (2015), a segurança ambiental implica também na oferta de recursos essenciais para o bem-estar da pessoa humana. Utiliza como exemplo, países em que há racionamento ou vedação do fornecimento de água, de saneamento, e de serviços sociais em geral, devido ao ambiente desgastado e insalubre, recorrente de exploração de recursos, ou nos quais ocorrem conflitos e guerras.

A degradação ambiental é gerada pelo homem e - é inegável põe em risco a continuidade da sua própria vida. Assim, como consequência de fatores econômicos - e das mazelas sociais, também derivadas ou agravadas por um modelo produtivo que vigora há 300 anos -, a degradação ambiental viola não só direitos específicos do indivíduo, como afeta principalmente a condicionante primária para a realização destes e de quaisquer outros direitos: a vida (AMORIM, 2015, p. 121)

Sirvinskas (2016) evidencia a importante atuação de programas na contemporaneidade que educam e conscientizam cidadãos, preferencialmente desde crianças, a compreender a necessidade de ter atitudes que não provoquem malefícios ao meio em que vivem, a fim de não promover danos a si mesmos e ao ecossistema em geral. Segundo ele, o modelo atual de desenvolvimento gera miséria e exclusão social, acompanhadas de desperdícios, considerando que a produção e o consumo desenfreados, para gerar vantagens econômicas, resultam em maior pressão sobre os recursos naturais. Deste modo, ocorre a degradação ambiental, e, como resultado, a diminuição de qualidade de vida. $\mathrm{O}$ autor defende que "é preciso incentivar as práticas ecologicamente corretas no nosso dia a dia, buscando um novo estilo de vida, calcado na ética e no humanismo, em resgatar e criar novos valores e repensar nossos hábitos de consumo" (SIRVINSKAS, 2016, p. 95).

É possível verificar que o avanço do ordenamento jurídico, no que tange aos direitos humanos, possibilitou a criação de uma proteção legal e internacional fundamental para o meio ambiente. Ações de conscientização e de regulamentação de atividades relacionadas ao ambiente tornaram-se 
imprescindíveis na busca de uma boa qualidade de ambiente, e de menor degradação de nossos recursos naturais.

\section{CONCLUSÃO}

Ao comparar as posições de estudiosos e especialistas no assunto, é perceptível que a relação entre Direitos Humanos e Direito Ambiental é ainda mais próxima do que se percebe. Como já exposto neste artigo, não é recente a compreensão de que o meio ambiente deve ser protegido, pois influencia não somente na vida humana, mas em tudo a qual necessita para ser vivida com dignidade. Através das diversas convenções e reuniões celebradas para discutir sobre o tema, foi alcançado um nível internacional de proteção, de forma a garantir que o Direito Ambiental integre um dos grandes direitos do ser humano.

Como já é evidenciado no art. 225 da Constituição Federal de 1988, é necessário um ambiente ecologicamente equilibrado para obter-se uma vida sadia, conforme debatido pelos autores mencionados, que descrevem histórica e socialmente as evoluções dos Estados diante da aceitação do meio ambiente saudável como direito fundamental e imprescindível para cumprimento dos direitos humanos.

Apesar das decisões de criar defesas para o ambiente serem elaboradas por seres humanos como forma de proteger sua natureza, estes são os causadores da maior parte de desastres e danos causados. Dar existência a leis que tutelam a ambiência não é suficiente se os seres que precisam seguilas não receberem educação e instruções sobre como agir de forma correta. A sociedade atual visa gerar benefícios, sobretudo econômicos, e ignora a relevância que possui o ambiente em que vive, que gera recursos, e proporciona produção, fabricação e construção de produtos e afins, que são essenciais para a coletividade. A exploração demasiada destes recursos desgasta o território, e tornou-se habitual, tendo em vista a vontade de criar exageradamente e, por conseguinte, desperdiçar, quando, de fato, tal exploração é uma das maiores causas da diminuição de qualidade de vida, e da ausência de cumprimento dos direitos fundamentais da pessoa humana.

\section{REFERÊNCIAS}

AMORIM, João Alberto Alves. A ONU e o Meio Ambiente: Direitos Humanos, Mudanças Climáticas e Segurança Internacional no Século XXI. São Paulo: Atlas, 2015. E-book. Disponível em: < http:/ /www.univates.br/biblioteca>. Acesso em: 29 abr. 2017.

BARROSO, Luís Roberto. A Dignidade da Pessoa Humana no Direito Constitucional Contemporâneo: Natureza Jurídica, Conteúdos Mínimos e Critérios de Aplicação. Versão provisória para debate público. Mimeografado, dezembro de 2010. 
BRASIL. Constituição (1988). Constituição da República Federativa do Brasil. Brasília, DF: Senado Federal: Centro Gráfico, 1988.

CANOTILHO, José Joaquim Gomes; LEITE, José Rubens Morato (Org.). Direito Constitucional Ambiental Brasileiro. 6. ed. São Paulo: Saraiva, 2015.

CASTILHO, Ricardo. Direitos Humanos. 3. ed. São Paulo: Saraiva, 2015.

FIORILLO, Celso Antonio Pacheco. Curso de Direito Ambiental Brasileiro. 16. ed. São Paulo: Saraiva, 2015. E-book. Disponível em: < http:/ / www.univates.br/ biblioteca>. Acesso em: 28 mar. 2017.

MAZZUOLI, Valerio de Oliveira. Curso de Direitos Humanos. 3. ed. Rio de Janeiro: Forense, São Paulo: MÉTODO, 2016. E-book. Disponível em: <http:/ / www.univates. br/biblioteca>. Acesso em: 28 mar. De 2017.

ORGANIZAÇÃO DAS NAÇÕES UNIDAS. https: / / nacoesunidas.org/ direitoshumanos/sistemaonu/. Acesso em 09 de agosto de 2019.

RAMOS, André de Carvalho. Curso de Direitos Humanos. 2. ed. São Paulo: Saraiva, 2015.

SIRVINSKAS, Luís Paulo. Manual de Direito Ambiental. 14. ed. São Paulo: Saraiva, 2016. E-book. Disponível em: < http:/ / www.univates.br/biblioteca>. Acesso em: 29 abr. de 2017. 